\title{
A Transmissão Psíquica Geracional
}

Generational Psychic Transmission

La Transmisión Psíquica Generacional
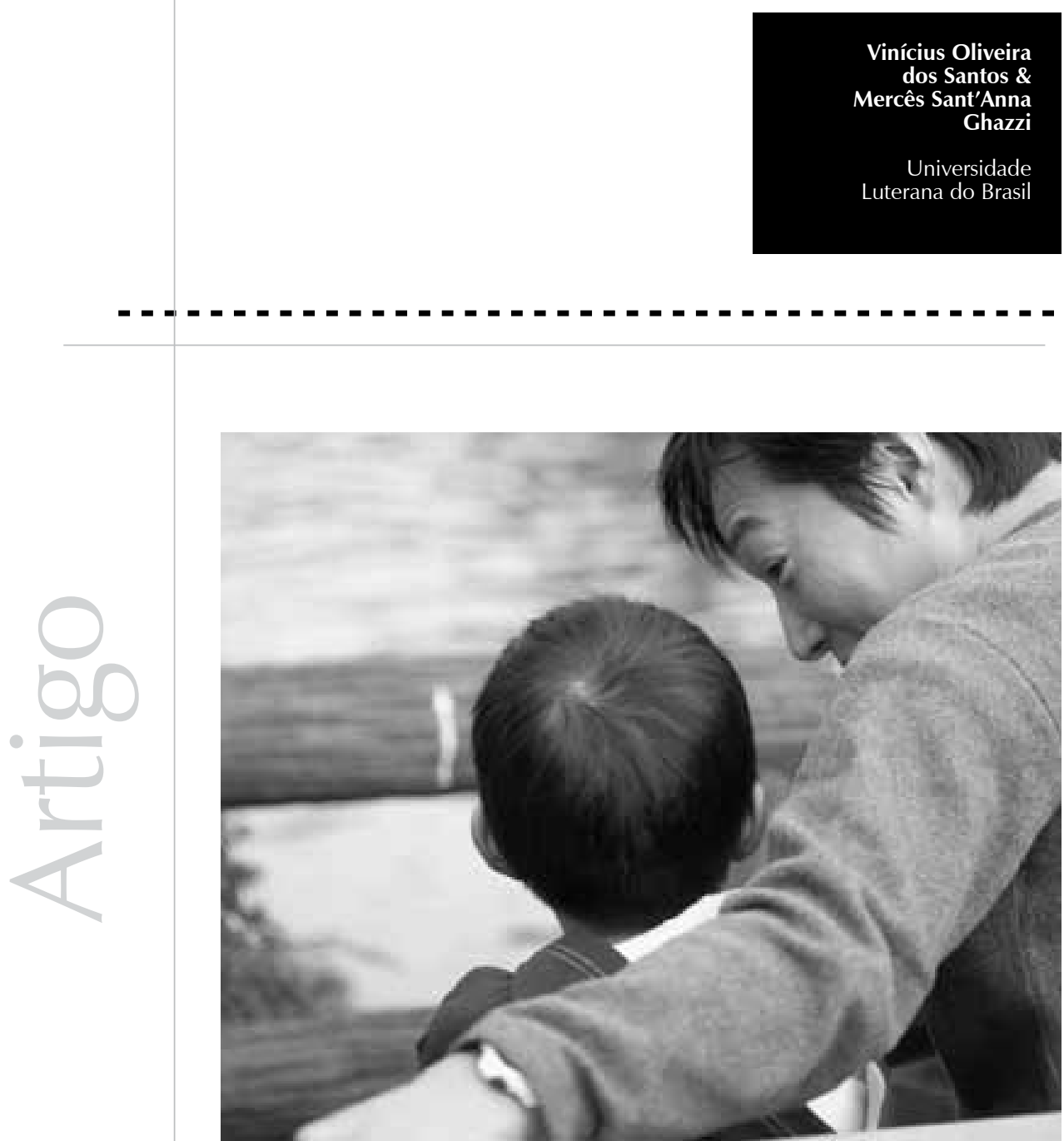
Resumo: $\mathrm{O}$ artigo seguinte refere-se a um estudo sobre como ocorre a transmissão psíquica entre as gerações e qual sua importância na constituição psíquica do sujeito. É também objetivo deste artigo explicar o que são as transmissões intergeracional e transgeracional. Para buscar respostas para essas questões, fez-se uma pesquisa bibliográfica sobre a transmissão psíquica, pelo viés psicanalítico, principalmente a partir da teoria lacaniana e com conceitos oriundos da linguística saussuriana. Será a partir de uma determinada ordem simbólica, constituída pela linguagem que precede o sujeito, nomeado por Lacan como o Outro, que a transmissão psíquica entre gerações ganhará o seu caráter unívoco, sempre se tendo em mente a importância fundamental do recalcamento e de seus efeitos, bem como do retorno do recalcado nas diferentes gerações. A transmissão psíquica é necessária e concomitante à constituição do sujeito, e ocorre através da linguagem, dos significantes que irão determinar uma ordem simbólica para o ser que nasce através dos diferentes discursos que perpassam as gerações nas figuras dos pais desse novo ser. Essa ordem simbólica continuará a se fazer presente nesse novo sujeito pelo restante de sua existência. Este artigo busca dar nova luz ao aspecto da transmissão psíquica transgeracional, diferenciando-se da recalque s abordagens psicanalíticas contemporâneas por ser uma leitura lacaniana. Serão usados dois exemplos: um de como a transmissão aparece na cultura, outro, na subjetividade do sujeito através da arte.

Palavras-chave: Transmissão psíquica entre gerações. Interação simbólica. Constituição do Sujeito. Psicoterapia psicanalítica. Psicanálise.

Abstract: The following article refers to a study on how mental transmission occurs between generations and its importance in the psychical constitution. It also aims to explain what are intergenerational and transgenerational transmissions. To answer these questions, there was a literature search on the psychic transmission, the psychoanalytical view, especially from the lacanian theory and Saussure's concepts. It will be from a particular symbolic order constituted by the language that precedes the subject, appointed by Lacan as the Other, that the psychic transmission between generations will obtain univocal character, always bearing in mind the fundamental importance of repression and its effects and the return of the repressed in other generations. The transmission is a necessary and concomitant psychic constitution of the subject through language, through the signifiers that will determine a symbolic order for the one to be born, through the different discourses that are transmitted beyond generations by the parents of this new being. This symbolic order will continue to be present in this new subject for the remainder of its existence. This article seeks to shed new light on the issue of intergenerational psychic transmission, which differentiates it from contemporary psychoanalytic approaches as a lacanian reading. Two examples will be given: one on how the transmission appears in the culture, another, on the subjectivity of the subject through art.

Keywords: Psychic transmission between generations. Symbolic interactionism. Constitution of the subect. Psychoanalytic psychotherapy. Psychoanalysis.

Resumen: El artículo siguiente se refiere a un estudio sobre cómo ocurre la transmisión psíquica entre las generaciones y cuál es su importancia en la constitución psíquica del sujeto. Es también objetivo de este artículo explicar lo que son las transmisiones inter-generacional y trans-generacional. Para buscar respuestas para esas cuestiones, se hizo una pesquisa bibliográfica sobre la transmisión psíquica, por la naturaleza psicoanalítica, principalmente a partir de la teoría de Jacques Lacan y con conceptos oriundos de la lingüística saussuriana. Será a partir de un determinado orden simbólico, constituido por el lenguaje que precede el sujeto, nombrado por Lacan como el Otro, que la transmisión psíquica entre generaciones obtendrá su carácter unívoco, siempre teniéndose en mente la importancia fundamental del recalcamiento y de sus efectos, así como del retorno de lo recalcado en las diferentes generaciones. La transmisión psíquica es necesaria y concomitante a la constitución del sujeto, y ocurre a través del lenguaje, de los significantes que van a determinar un orden simbólico para el ser que nace a través de los diferentes discursos que pasan las generaciones en las figuras de los padres de ese nuevo ser. Ese orden simbólico continuará haciéndose presente en ese nuevo sujeto por el resto de su existencia. Este artículo busca dar nueva luz al aspecto de la transmisión psíquica trans-generacional, diferenciándose de los abordajes psicoanalíticos contemporáneos por ser una lectura lacaniana. Serán usados dos ejemplos: uno de cómo la transmisión aparece en la cultura, otro, en la subjetividad del sujeto a través del arte.

Palabras clave: Transmisión simbolica psiquica entre las generaciones. Interación simbólica.

Constituición del sujeto. Psicoterapia psicanalítica. Psicoanálisis. 
O seguinte artigo tem como objetivo demonstrar a importância da transmissão psíquica entre as gerações na constituição subjetiva, visando também a elucidar os conceitos de transmissão intergeracional e transgeracional.

Para analisar essas questões, partiu-se de estudos psicanalíticos, em articulação com os elementos de linguística estrutural. $\mathrm{O}$ percurso que será realizado terá como particularidade a diversidade de autores, desde Sigmund Freud até as referências mais atuais sobre o assunto, passando pelo ensino de Lacan. A ordem simbólica será o ponto de ancoragem para a transmissão psíquica entre as gerações, sendo a transmissão entendida como necessária e concomitante à constituição do sujeito. Parte-se da hipótese que o sujeito só pode se constituir como tal através da relação com o outro, e o outro, a partir da linguagem. Sendo assim, o campo do simbólico será determinante, pois revela, a partir de sua eficácia na constituição subjetiva, como o sujeito vai apropriar-se de sua história ou se ficará aprisionado nela, em uma relação em que predomina o imaginário.

As diferentes formas de transmissão (transgeracional e intergeracional) serão discutidas através dos conceitos encontrados em alguns autores da literatura psicanalítica contemporânea buscando-se um entendimento diferenciado em relação a um dos conceitos: o de transgeracionalidade. Tentar-se-á compreender esse tipo de transmissão a partir dos diferentes modos de negação que o sujeito utiliza para lidar com a castração, ou seja, os meios que descobre para dar conta das vicissitudes da vida e de suas frustrações, traumas, doenças, etc. O modo como o sujeito vai enfrentar essas sucessivas castrações dependerá da bagagem simbólica que foi transmitida pela geração precedente. Os efeitos do recalcamento nas gerações e seus respectivos retornos também serão decisivos para a transmissão, dando-lhe, inadvertidamente, um caráter singular.
Para o desenvolvimento dessa temática, foi realizada uma pesquisa bibliográfica conforme as etapas propostas por Gil (2010), seguindo um caráter exploratório e uma abordagem qualitativa. Pertencendo ao campo psicanalítico, este estudo também se caracteriza por ser uma pesquisa históricoconceitual, que é aplicada em trabalhos que enfatizam a teoria psicanalítica, objetivando o estudo da construção dos seus conceitos. Nesse processo, utiliza-se o material bibliográfico já elaborado e reescreve-se, conforme a temática, o perfil do fenômeno pesquisado, aprimorando-se os conceitos já estabelecidos e favorecendo-se a sua compreensão teórica (Mezan, 1994).

Pensar na transmissão psíquica entre gerações é abrir caminho para diversas teorizações a respeito de como somos constituídos e qual a consequência disso. Tal processo nos traz subsídios para pensarmos na transmissão cultural e nos efeitos do recalcamento nas questões sociais e culturais, as quais acabam retornando sob aspectos diferenciados, que passam, por vezes, despercebidos. A importância do tema foi reconhecida há relativamente pouco tempo, sendo uma área nova no que concerne à psicanálise, embora o próprio Freud fizesse diversas menções ao fato em alguns de seus escritos.

Começou-se a trabalhar mais com essas questões principalmente a partir do paciente psicótico e de sua família: diversos autores se questionavam sobre o papel da família na doença que acomete um de seus membros, vide os trabalhos de Abraham e Torok (1971/1995), Kaës (1997), Granjon (2000), Faimberg (1993) e Eiguer (1998), entre outros autores. A preocupação central dos autores era buscar compreender o aspecto patológico da transmissão, sendo este originado pela impossibilidade de simbolização de situações traumáticas vividas.

A relevância do tema está na compreensão de que o seu aprofundamento é capaz de 
"Esse assassinato

(...) postula

de maneira contundente

o sujeito como herdeiro do

crime dos

ancestrais. Todos compartilham os sentimentos de culpa daí advindos" (InglezMazzarella, 2006, p. 41). constituir um importante potencializador da escuta do paciente, de seu sofrimento psíquico, ou seja, há uma ampliação da escuta a partir da consciência dos fenômenos de transmissão psíquica, pois todos aqueles que se aventuram na arte da escuta estarão em contato com um sujeito que se constitui por meio de sua relação com o outro e o Outro, logo, com suas gerações precedentes. Pela experiência com atendimentos clínicos, pudemos notar aspectos dessa transmissão psíquica que impediam o paciente de tomar seu próprio rumo, de tornar-se ator de sua própria história, como se tivesse que prestar contas aos seus antecessores, e foi a partir daí que começamos a nos interessar pelo tema. Além disso, destacar a dimensão negativa da transmissão faz com que possamos reconstruir aspectos que impedem tanto o paciente como comunidades inteiras de prosseguir em sua história, de fazer a sua própria história.

Para ilustrar o trabalho, tomaremos algumas produções culturais: uma obra literária que demonstra aspectos desse tipo de transmissão e de seus efeitos sobre o estilo do autor, bem como referências a manifestações, na cultura, de transmissões permitidas ou negadas e das consequências dessa permissão ou negação. Demarcamos que não pretemos, aqui, discutir a formação de sintomas clínicos a partir das obras ou manifestações culturais exploradas, mas sim, articular esses conceitos a partir de exemplos que lançam luz sobre os efeitos da transmissão no devir dos sujeitos e de toda uma cultura.

\section{Surgimento do tema na obra de Freud}

Em relação aos textos freudianos, em muitos momentos, há considerações relevantes que contribuíram para o surgimento do tema na psicanálise contemporânea. Freud (1913/2006a), em seu texto Totem e Tabu, ressalta o quanto a proibição do incesto e do homicídio organizam não apenas a sociedade mas também o sujeito. O sentimento de culpa que emerge após o assassinato do pai nos dá uma das dimensões da transmissão psíquica entre gerações: "Esse assassinato (...) postula de maneira contundente o sujeito como herdeiro do crime dos ancestrais. Todos compartilham os sentimentos de culpa daí advindos" (Inglez-Mazzarella, 2006, p. 41).

Freud afirma que nem mesmo o recalque bem sucedido elimina vestígios, o que possibilita a formação de elos entre as gerações a partir desse mecanismo de defesa. No texto Sobre o narcisismo: uma introdução, o autor fala de uma transmissão psíquica por meio das gerações pela via narcísica, deixando claro que o filho será investido, através do narcisismo dos pais, tornando-se depositário dos desejos insatisfeitos destes:

Se prestarmos atenção à atitude de pais afetuosos para com os filhos, temos de reconhecer que ela é uma revivescência e reprodução de seu próprio narcisismo, que de há muito abandonaram. (...) Assim eles se acham sob a compulsão de atribuir todas as perfeições ao filho - o que uma observação sóbria não permitiria - e de ocultar e esquecer todas as deficiências dele (Freud, 1914/2006b, p. 97)

Com os conceitos apresentados em O Ego e o Id, Freud (1926/2006c) também faz referência à transmissão psíquica geracional, sobretudo com os conceitos de Supereu, Ideal de Eu e Eu ideal. O Supereu é entendido como herdeiro do complexo de Édipo e como transmissor das proibições e das coerções dos pais à criança. Quanto ao conceito de Eu ideal, Freud assim o denominou para demonstrar a imagem idealizada do Eu construída pelos pais e projetada no filho, sendo uma via de busca do sujeito de um narcisismo dos pais que foi abandonado por estes devido às exigências da realidade. Já o Ideal de Eu lança o sujeito para o futuro, em busca da completude narcísica perdida: "O ideal de eu, alcançado por meio da estruturação do supereu, pode 
ser entendido como um devir, como uma promessa de recuperação da vivência de completude" (Inglez-Mazzarella, 2006, pp. 72-73).

Eu ideal e Ideal de Eu ficarão, sempre, distantes um do outro, pois, no momento em que o sujeito alcança supostamente o Eu ideal, logo sentirá (por meio da falta inerente que nos constitui) que há algo mais a ser conquistado. Falamos, então, do Ideal de Eu, que projeta sua busca na rede simbólica, afetada pelo meio que marca o sujeito, e logo referida à história das gerações.

\section{Compreensão do tema - pós- freudianos}

Os estudos sobre a transmissão psíquica geracional buscam responder a uma clínica de casos conhecidos como casos difíceis, com ênfase nos estados patológicos de luto, traumatismos, sofrimentos narcísicos e expressões da perversão. São Abraham e Torok (1971/1995) os iniciadores da discussão, principalmente a partir da publicação do livro A Casca e o Núcleo, em que retomam conceitos como o de introjeção, de Ferenczi, e incorporação, de Melanie Klein. Esses autores se notabilizaram por afastarem-se das duas correntes dominantes no pensamento psicanalítico da época, a kleiniana e a lacaniana, questionando conceitos que estão na raiz do pensamento psicanalítico (Inglez-Mazzarella, 2006). A preocupação central dos autores era buscar compreender o aspecto patológico da transmissão, sendo este originado pela impossibilidade de simbolização de situações traumáticas vividas. Conforme Correa, esses psicanalistas elaboraram conceitos essenciais para a clínica psicanalítica contemporânea, tais como os "efeitos dos segredos de família atravessando as gerações (...), o luto impossível de uma pessoa significativa (que se torna patológico), a identificação secreta com um outro (fantasma de incorporação), e o enterro intrapsíquico de uma vivência vergonhosa e indizível (cripta)" (2000, p. 09).

O modo como procuraremos elucidar as questões relativas à transmissão psíquica geracional estará de acordo com a teoria lacaniana e com conceitos oriundos da linguística saussuriana, portanto, diferencia-se das abordagens que introduziram o tema na clínica psicanalítica contemporânea.

\section{Signo linguístico, significante e transmissão psíquica}

Para entendermos o ponto de vista defendido neste artigo, algumas premissas se fazem necessárias. Primeiro: a hipótese sustentada é que a transmissão psíquica se dá não apenas por meio de processos conscientes, mas, fundamentalmente, por processos inconscientes; segundo: entendemos o inconsciente conforme um dos aforismos lacanianos, ou seja, o inconsciente estruturado como linguagem.

É na linguagem, no simbólico, que procuraremos respostas relativas à transmissão psíquica, sendo o simbólico um campo constituído por leis, por um "código específico para cada povo (a língua) e pela cultura (conjunto de costumes, regras e sistemas de parentesco que são transmitidos de uma geração para a seguinte)" (Bernardino, 2006, p. 24). Quanto ao conceito de significante, este pode ser definido como:

(...) Um termo tomado por Lacan da Linguística para garantir o caráter simbólico da linguagem, em contraposição à mensagem. Em vez de mensagem, fala-se de uma cadeia significante que produz efeito de sentido a posteriori, ou seja, na articulação produzida na relação entre significantes que, em si mesmos, não têm sentido. Este conduz à dimensão da verdade do sujeito, ou seja, à revelação do inconsciente (Rosa, 2001, p. 135)

Toda família tem seus significantes, adquiridos através da ordem simbólica relacionada ao 
modo como receberam esses significantes e a quais significados ficaram associados a estes. Os significantes, de modo geral, podem ser descritos como "essas marcas e palavras que nos representam e dão origem ao nosso desejo" (Bernardino, 2006, p. 30).

Para falarmos de transmissão de significantes, tomamos o conceito de signo linguístico, apresentado por F. de Saussure, em seu Curso de Linguística Geral:

(...) O signo linguístico une não uma coisa e um nome, mas um conceito e uma imagem acústica. Esta última não é o som material, coisa puramente física, mas a marca física desse som, a representação que nos é dada por nossos sentidos; ela é sensorial (1993, p. 28)

O signo linguístico se torna, então, a relação de um significado (conceito) a um significante (imagem acústica). Algumas propriedades do signo precisam ser explicadas. Primeiro, o signo comporta uma dimensão de arbitrariedade. Essa dimensão é explicada devido ao fato de que o significante é livremente escolhido pelo sujeito de acordo com a ideia que ele representa, ou seja, recebemos determinado significante (podemos pensar em algo transmitido pela família), mas, a partir do que dele decodificamos, alteramos a utilização anterior do signo linguístico (a sua significação), ficando o significante e a sua significação dependentes da livre escolha do sujeito (Dor, 2003). Esse primeiro aspecto do signo demonstra como a transmissão ocorre de modo particular, de acordo com o que o sujeito interpreta e elabora dos significantes transmitidos, e de acordo com aqueles que recalca.

Nesse caso, temos uma arbitrariedade do signo ligada estritamente ao caráter subjetivo, não sendo mais uma arbitrariedade própria de uma comunidade linguística. À medida que tratamos do arbitrário do signo próprio do sujeito, a associação significado/ significante pode ser considerada totalmente submetida às possibilidades de combinações aleatórias, eventuais, o que demarca mais uma vez o aspecto singular da transmissão psíquica e daquilo que o sujeito simbolizará dela.

A arbitrariedade do signo se exemplifica pela existência de inúmeras línguas, que designam os mesmos conceitos por intermédio de diferentes sons e também pela pluralidade de significados que um mesmo significante apresenta (Jorge, 2005). Quanto à imutabilidade do signo, refere-se à imposição, à comunidade linguística, da escolha do sujeito de um significante, o que submete essa comunidade à língua. Trata-se de uma convenção arbitrária do signo, que instala esse signo em uma tradição, no tempo (Dor, 2003).

Tudo se passa como se a língua tivesse um certo caráter de fixidez, a partir do consenso que a comunidade linguística adota em relação a ela. Existe uma ligação entre os dois fatores: o signo possui esse caráter de fixação porque foi escolhido livremente através do tempo, mas, de modo paradoxal, é a dimensão do tempo que vai impor ao signo uma certa alteração. A influência do fator tempo é diretamente dependente da natureza do significante, ou seja, é pela fixação do signo que ele resiste através do tempo, mas é pelo tempo que esse signo será modificado.

Nesse sentido, tomamos o romance de Paul Auster A Invenção da Solidão (1982/1999) como exemplo interessante da transmissão de um significante. Nessa obra, o personagem, após a morte do pai, escreve sobre ele, buscando respostas sobre sua ausência, seu modo distante e falta de apego para com as pessoas e coisas. O autor relata a lembrança de um dos poucos momentos em que teve a companhia realmente presente do pai, quando este Ihe contava histórias: naquele 
momento, o pai parecia autêntico, contava histórias de um modo que só ele poderia contar. Esse estilo marca sua vida literária: "Era uma história de intensa aventura, repleta de perigos mortais (...); sua linguagem era elegante e rebuscada, talvez um eco dos livros que ele mesmo lera quando menino. Mas foi exatamente esse estilo literário que me encantou" (1982/1999, p. 30). Mesmo sabendo, anos depois, que a história era fictícia, ele lembra o quanto relutava em aceitar isso, como que para garantir alguma verdade naquela autenticidade: "Eu ainda tinha a sensação de que devia haver alguma verdade ali. A história me dava algo a que me agarrar, em relação a meu pai, e eu relutava em abrir mão daquilo". Nesse sentido, vimos o quanto o momento de cumplicidade com o pai, momento raro de uma pessoa considerada distante por todos, classificada pelo personagem como um homem invisível, o marcou. Não era só a história em si, não seu conteúdo, mas tudo o que ela representava de um momento quase que único de elo entre pai e filho. Não é de surpreender que essa marca fosse transmitida sob a forma do amor do filho às histórias, como um significante que representava um outro traço do pai, indo além de sua ausência.

Podemos fazer uma analogia com o filme Homem Invisível, de James Whale (1933), no qual, apesar de ninguém vê-lo, suas pegadas ficavam marcadas no chão, isto é, ele deixava rastros por onde passava. O invisível do pai, em Auster, deixa suas pegadas através dos significantes, que, nesse caso, ganham corpo através da obra literária, saindo do esquecimento, onde poderiam provocar eventos sintomáticos.

\section{Transmissão psíquica e constituição psíquica do sujeito}

Vimos acima o quanto, ao falarmos do signo linguístico, podemos esclarecer as vias de transmissão simbólica que afetam o sujeito.
Sempre que falamos de significantes, falamos de função simbólica, e, em consequência, do inconsciente:

O inconsciente deixa de ser o inefável refúgio das particularidades individuais, o depositário de uma história única, que faz de cada um de nós um ser insubstituível. Ele se reduz a um termo pelo qual nós designamos uma função: a função simbólica, especificamente humana (Lévi-Strauss, 1973, p. 234)

A transmissão se dará pelas palavras, pelos significantes, mas também por aquilo que não é dito, pois significantes podem ser transmitidos também através daquilo que simbolizamos das imagens, dos sons (imagem acústica), já que "a transmissão ocorre apesar do não-dito, dado que se fundamenta (...) no desejo do Outro" (Rosa, 2001, p.128). Ela pode ocorrer exatamente por algo não ter sido dito de forma manifesta, pelo que foi recalcado, "o que não está dito, recoberto pelo já dito, é o que permite movimentar a cadeia significante para produzir novos sentidos" (Rosa, 2001, p.126).

Pensando sobre a transmissão psíquica e sobre o modo como opera a partir do que não é dito, remeto-me novamente a Auster. No livro, ao saber da morte do pai, vê-se impelido a escrever sobre ele:

\footnotetext{
"Pensei: meu pai se foi. Se eu não agir depressa, sua vida inteira vai desaparecer junto com ele", e a seguir, diz: "O que me perturbava era outra coisa, algo que não tinha a ver com a morte nem com minha reação a ela: a compreensão de que meu pai não deixara vestígios" (Auster, 1982/1999, p.12)
}

Ele conta, com detalhes, o quanto a ausência do pai o toca e como essa característica paterna influenciou sua obra. Questiona-se: não fosse a ausência e a dificuldade do pai em falar de si, teria ele desejado falar do pai? O pai nunca falava de si mesmo, não parecia saber que havia alguma coisa sobre a qual 
..."não impede o representante pulsional de continuar existindo no inconsciente, de continuar a se organizar, de formar novas representações derivadas e de estabelecer ligações" (Freud, 1915/2004, p. 179). pudesse falar: "Caso tivesse havido outra coisa que não o silêncio, eu teria ao menos sentido necessidade de falar?" (1982/1999, p. 27). O que foi transmitido, após a morte do pai, foi o sentimento de que este não deixara vestígios, e que, depois de um curto tempo de luto, ninguém mais se lembraria dele, "enfim, seria como se ele nunca tivesse existido". Essa marca da ausência como significante faz com que o filho tente ressignificá-la através do livro, como que para garantir o legado paterno para as futuras gerações. Como ele mesmo conta: "Se, enquanto estava vivo, eu andava sempre em busca dele, sempre tentando encontrar o pai que não estava presente, agora que ele está morto, ainda tenho a sensação de que devo continuar à sua procura" (p. 13).

O personagem tenta, assim, produzir significantes que ofertem um novo sentido à figura do pai, como que para justificar sua característica fundamental: a ausência. Essa característica fica marcada em algumas passagens: "Conversar com ele era uma experiência penosa (...). A gente falava, e não tinha resposta, ou então vinha uma resposta incongruente, demonstrando que ele não estava acompanhando as nossas palavras" (p. 24). Essa falta de resposta marca o autor, que passa a escrever o romance como que para justificá-la. O mais fascinante dessa procura por um novo sentido é a história do assassinato de um avô, supostamente morto pela mulher, sua avó. No mito familiar, circulam relatos contraditórios: "Na minha própria infância, ele me contou três histórias distintas sobre a morte de seu pai" (p. 42). São várias histórias, várias versões que a novela familiar permite, a cada sujeito, construir a partir dos significantes que Ihe são legados. É a partir da busca por respostas quanto à ausência paterna que o personagem descobre os não ditos familiares, podendo ter acesso à verdade, dando nova luz à figura do pai.
Assim, pode-se destacar o quanto as vicissitudes da vida do personagem e de seus antecessores aparecem em seu discurso influenciando sua escolha pela carreira literária, o que só vem a se tornar consciente após a morte do pai, evento a partir do qual emergem os conteúdos recalcados. Vemos que o que foi recalcado pelo pai do personagem acaba retornando a partir da figura do filho, demonstrando que o recalcamento não impede que a transmissão ocorra, pois o recalque "não impede o representante pulsional de continuar existindo no inconsciente, de continuar a se organizar, de formar novas representações derivadas e de estabelecer ligações" (Freud, 1915/2004, p. 179).

Se falamos em transmissão através do inconsciente e entendemos o inconsciente como função simbólica determinada por significantes, vejamos agora de que modo o inconsciente se forma para a criança e de onde partirá toda a cadeia significante, responsável pela transmissão psíquica. Esse caminho irá rumo ao problema colocado, a saber, qual a importância da transmissão psíquica na constituição do sujeito. Veremos que a transmissão psíquica é necessária e concomitante com a constituição do sujeito. Sabemos que toda criança já está sendo constituída psiquicamente mesmo antes de seu nascimento através de um banho de linguagem. Esse banho existe no seio de sua família, e se dá pelo encontro de duas linhagens. Cada uma terá sua história com os ditos e os não ditos, que fazem sua especificidade (Szejer, 1997). Nesse banho de linguagem, estarão diversos significantes que serão transmitidos pelos pais e pelas pessoas que estão ao redor da criança, sempre considerando a cultura em que a família está inserida. Nessa perspectiva, a formação do sujeito ocorre através da relação com o outro e o Outro (linguagem). O conceito de intersubjetividade é assim exposto: 
A intersubjetividade é, de início, dada pelo manejo do símbolo, e isso desde a origem. Tudo parte da possibilidade de nomear, que é, ao mesmo tempo, destruição da coisa e passagem da coisa ao plano simbólico, graças ao que o registro propriamente humano se instala. É daí que se produz, de maneira mais e mais complicada, a encarnação do simbólico no vivido imaginário (Lacan, 1954/1998a, p. 250)

O surgimento do sujeito psíquico dependerá do encontro de duas estruturas: a estrutura biológica do ser humano, com tudo o que ela comporta, e uma estrutura familiar, pela qual se transmite o sistema simbólico (Bernardino, 2006). Daqui se nota que, sem transmissão psíquica, não há sujeito psíquico, e, portanto, não há constituição psíquica do sujeito. Pensemos, então, na criança que acaba de nascer. Ela precisa ocupar um lugar na família, uma posição subjetiva, precisa modificar as posições familiares estabelecidas até então. É um lugar pleno de determinações simbólicas, onde cada bebê vem dar seguimento a uma família que tem uma história de várias gerações, herdando não apenas a carga genética mas também os acontecimentos, as experiências significativas vividas pelos familiares, sejam estas simbolizadas ou não. O modo como a criança será concebida e receberá significado dependerá de inúmeros fatores da história que a precedeu, dos significantes que ficaram marcados na família. É aquilo de que falávamos a respeito do caráter de fixação do signo e da sua capacidade de ser alterado por meio da combinação aleatória significante/ significado.

Ao bebê, enquanto não encontra seu próprio sentido, resta corresponder ao sentido que Ihe dão aqueles que estão ao seu redor, ao lugar que recebe na família, pois, se não ocupar esse lugar, não haverá nenhuma referência para ele, enfim, não encontrará significado algum para si próprio. A esse processo de corresponder ao sentido dado por um outro, Lacan (1975) denomina alienação. É necessário alienar-se ao desejo e às palavras de um outro humano para ter existência simbólica, neste caso, o Outro Primordial (a mãe), entendido como um "Outro encarnado que enlaça, que sujeita esse bebê à ordem simbólica" (Jerusalinsky, 2005, p. 03, itálicos do autor).

Vemos, assim, que o sujeito vai construir suas significações a partir de uma rede simbólica anterior e exterior a ele. Vai levar um tempo para que a criança possa falar por si mesma, pois primeiro a linguagem vai marcá-la, para que, posteriormente, ela possa ser realmente sujeito desejante. Para isso, será preciso uma segunda operação psíquica, a separação, "que desalienará o sujeito do saber e das palavras desse Outro, para que ele tenha uma existência simbólica própria" (Bernardino, 2006, p. 26). É ao se dar conta de que esse Outro é faltoso que o bebê vai começar a se questionar sobre seu próprio desejo. A saída da alienação se dá a partir do surgimento da falta para a mãe, e, para que isso aconteça, será necessária a entrada de um terceiro: o pai, ou alguém que exerça a função paterna.

Essa tarefa de romper a linguagem que a marcou, que veio dos outros parentes, e que a introduziu no campo das palavras, não será nada fácil. A criança terá que recalcar essas marcas primordiais, esquecê-las, torná-las inconscientes, para assim ter acesso à fala; será, então, sujeito de sua própria história.

No que se refere ao inconsciente, este é estabelecido para a criança a partir do controle simbólico do objeto perdido do desejo (Dor, 2003). O objeto de desejo da criança estará ligado a uma fantasia de completude entre a mãe e a criança, na qual a última estará fantasiosamente na posição de falo da mãe, ou seja, de objeto que preenche a falta do 
Outro. É o aparecimento da linguagem que vai tornar-se "signo incontestável do controle simbólico do objeto perdido, através da realização da metáfora do Nome-do-Pai, sustentada pelo recalque originário" (Dor, 2003, p. 90). O recalque originário aparece como processo estruturante, e consiste em uma metaforização que é o próprio ato da simbolização primordial da Lei, que se efetua na substituição do significante fálico pelo significante Nome-do-Pai (Dor, 2003).

A captura como objeto de desejo da mãe inaugura a cadeia simbólica, através do S1, o significante fálico, nomeado também significante do desejo da mãe (Dor, 2003). $\mathrm{O}$ aparecimento do sujeito inconsciente ocorre, então, através do esforço da criança em designar simbolicamente sua renúncia ao objeto perdido. O recalque do significante fálico (S1) é o que inaugura a cadeia falada, sendo que esse significante permanece provisoriamente no inconsciente. Seu substituto será o que se chama de S2, o significante Nome-do-Pai. Para entendermos como ocorre essa substituição, pensemos o seguinte: em um determinado momento de sua evolução edipiana, a criança é conduzida a associar a ausência da mãe à presença do pai. Nesse momento, o pai aparece à criança como um objeto fálico rival, para depois ser representado como aquele que detém o falo. Uma relação significante é elaborada pela criança a partir do momento em que ela pôde nomear a causa das ausências de sua mãe, invocando a referência do pai que tem o falo. É aqui, em especial, que intervém o Nome-do-Pai associado à Lei simbólica que ele encarna (Dor, 2003). O S1 foi recalcado devido à sua substituição pelo S2, que, de agora em diante, estará associado ao significado do desejo da mãe. Logo, "nomeando o pai, a criança continua na realidade a nomear ainda o objeto fundamental de seu desejo.
Mas agora ela o nomeia metaforicamente, uma vez que se tornou inconsciente para ela" (Dor, 2003, p. 93). Como afirma Jorge (2005), o núcleo do inconsciente é real, é uma falta originária constituída pela perda do objeto do desejo, e é em torno dessa falta que o inconsciente se estrutura. A função paterna é imprescindível para a constituição psíquica da criança, caso contrário, esta pode ficar em posição de objeto do desejo do outro.

Vimos como a transmissão psíquica geracional estará relacionada com a transmissão de significantes e com a função paterna, que estruturam o psiquismo da criança. Os efeitos do recalcamento, o caráter fixo e, ao mesmo tempo, móvel do signo linguístico, a função do Outro encarnado, todos esses aspectos serão decisivos do modo como a transmissão acontecerá.

\section{Transmissão intergeracional e transgeracional}

Na literatura psicanalítica, encontra-se referência a duas modalidades de transmissão psíquica: transmissão intergeracional e transgeracional. A transmissão psíquica intergeracional é entendida como um trabalho de ligações e de transformações, no qual a passagem de uma geração à outra é acompanhada por uma modificação daquilo que é transmitido. Isso implica uma receptação, um acolhimento daquilo que foi transmitido por aquele que recebe a transmissão (Granjon, 2000). Deve haver uma distância entre o transmissor e o receptor, de modo que este último possa modificar o que lhe foi transmitido, possa simbolizá-lo, enfim, possa se apropriar da transmissão. Esse aspecto fundamental da transmissão é o que se entende por transmissão psíquica intergeracional: está entre as gerações, sendo seu conteúdo modificado conforme o tempo e a capacidade de cada geração de simbolizar a história de seus antepassados. 
Mas esse trabalho de transmissão pode falhar, sendo a transmissão alienante, e não estruturante para o sujeito. Essa é a transmissão psíquica transgeracional, que é um tipo de transmissão que ocorre sem modificações, "atravessa as gerações e se impõe em estado bruto aos descendentes" (Granjon, 2000, p. 24), e que é considerada por alguns autores da literatura psicanalítica contemporânea como a dimensão negativa da transmissão, sendo o negativo utilizado como substantivo que se refere à ausência de representação ou de representabilidade. A autora, em consonância com InglezMazzarella (2006), explica que, nesse tipo de transmissão, aquilo que é transmitido não pode proporcionar modificações que permitam uma integração psíquica do sujeito, não havendo possibilidade de simbolização de situações traumáticas. Nada pode escapar à transmissão:

Nenhuma falta, nenhuma transgressão, nenhuma morte, nenhum delito (...) podem ser abolidos, obrigados a serem transmitidos, inclusive com os impedimentos, interditos, mecanismos de defesa que eles suscitam e colocados para evitar que sejam conhecidos (...), fazendo fracassar as formações e os processos capazes de metabolizá-los, de torná-los pensáveis, de integrá-los em uma psique e em uma história (Granjon, 2000, p. 25)

O que será transmitido será o traço daquilo que se passou e que não pôde ser pensado, é um tipo de transmissão pelas gerações e não entre as gerações, o que denota a dificuldade de transformação daquilo que é herdado simbolicamente. Conforme Granjon, essa transmissão também diz respeito "aos objetos capazes, ou em curso de transformação, quanto aos objetos não transformáveis (...), não passíveis de inscrição, enquistados ou encriptados, elementos foracluídos, recusados, clivados" (2000, p. 26).

Em relação à transmissão psíquica transgeracional, vamos considerá-la a partir das formas de negação usadas para dar conta das vivências traumáticas, questão enfatizada pelos autores que dela se ocupam. Pensamos que é por essa via que podemos explicar a falta ou a impossibilidade de simbolização do que é transmitido.

De acordo com Quinet (2007), é a partir do simbólico que podemos nos referir aos três modos de negação do Édipo (negação da castração do Outro), que correspondem às três estruturas clínicas. Na neurose, $\mathrm{O}$ recalque nega conservando o elemento no inconsciente; na perversão, o desmentido (renegação) o nega, conservando-o no objeto fetiche. Já na psicose, a forclusão é um modo de negação que não deixa nenhum vestígio, não conserva nada, arrasa. Cada modo de negação é simultâneo a um tipo de retorno do que é negado (Quinet, 2007). No recalque, por exemplo, o que é negado no simbólico retorna no mesmo registro, seja sob a forma de sintoma neurótico, seja através das formações do inconsciente, como atos falhos, lapsos e sonhos. Na psicose, "o significante retorna no real, apontando a relação de exterioridade do sujeito com o significante, como aparece, de uma forma geral, nos distúrbios de linguagem" (Quinet, 2007 , p. 20). Na forclusão, "estamos diante de uma falta de repressão originária que produz uma falta de significante. Há uma falta de coerência para dar origem aos significantes e, assim, o negativo, neste caso, iguala-se ao vazio, ao nada" (InglezMazzarella, 2006, p. 88). Quanto ao desmentido, recai sobre os significantes não verbais, "o que requer do trabalho de análise a reconstrução dos aspectos que constituíram a clivagem" (2006, p. 89). É, então, a partir do modo como cada geração vai lidar com a castração, entendida aqui não apenas no seu sentido de organização estrutural mas também como as várias castrações que temos que lidar na vida, que será decidido o modo como estas vão ser transmitidas para as gerações futuras. 
Inglez-Mazzarella, ao citar a obra de René Kaës Transmissão da Vida Psíquica entre_Gerações, expõe a ideia de que a transmissão tem seu campo estendido para além dos significantes propriamente ditos e dos desejos que nos precedem, acrescentando os significantes "congelados, enigmáticos, brutos, sobre os quais não se operou um trabalho de simbolização" (2006, p. 86). Mais adiante, dirá que o que não encontra inscrição na vida psíquica dos pais ou das gerações precedentes e que vem depositar-se na psique da criança opera como aspecto da dimensão negativa da transmissão. Nesse sentido, remetemos ao que foi negado e ao suporte simbólico das gerações precedentes, tomando como exemplo a psicose. Sabemos, com Lacan, que, para haver um psicótico, é preciso haver no mínimo três gerações: "A primeira viveu uma experiência traumática, apartada na segunda (não encontra possibilidade de representação) e apresentada na terceira em forma de delírio" (Inglez-Mazzarella, 2006, p. 51, itálico da autora). O psicótico presentifica, em seu sofrimento, toda uma gama de significações que ficou fora da cadeia simbólica, por isso o estranhamento do psicótico com seu delírio, pois aquilo que retorna no real nunca fez parte dele mesmo. Notamos que a transmissão psíquica transgeracional, com sua dimensão negativa, engloba tanto a neurose como a perversão e a psicose, pois em todas elas há não ditos, mas, em cada caso, os não ditos são significados de forma diferente ou, no caso da psicose, não são significados, são vivenciados nos delírios. Nesse sentido, podemos lançar a questão de que, no trabalho de análise de um psicótico, com a tentativa de dar significado aos seus delírios, talvez haja possibilidade de alguma significação para esse sujeito daquilo que ficou fora da cadeia, ou, nas palavras de alguns autores psicanalíticos contemporâneos, daquilo que ficou encriptado, enigmático para o sujeito. Nas neuroses, trata-se de buscar a reconstrução do que ficou paralisado em uma significação dada pelas gerações precedentes, para que o sujeito busque sua própria significação. O romance de Auster mostra um exemplo da busca de uma nova significação que ficou paralisada, nesse caso, a ausência paterna. O filho busca, nas fotos da família, após a morte do pai, uma verdade a ser descoberta: "Parecia que elas poderiam me dizer coisas que eu nunca havia sabido, me revelar alguma preciosa verdade oculta, e estudei cada uma delas com toda a atenção (...); eu queria que nada fosse perdido" (1982/1999, p.21). É a partir da investigação das fotos e documentos familiares que o filho descobre os não ditos familiares, marcados pelo assassinato de seu avô pela avó. Tudo se passa como se o filho recebesse uma transmissão com um buraco, em que a ausência paterna deixa uma lacuna aberta para novos significados. Assim, o filho, ao não aceitar essa transmissão em estado bruto, a questiona, e com isso dá nova significação à figura do pai a partir de sua investigação do legado familiar. Como ele mesmo afirma: "O fato de eu nunca ter visto antes muitas dessas fotografias me dava a sensação estranha de que eu o encontrava pela primeira vez, de que uma parte dele só agora começava a existir. Eu havia perdido meu pai. Mas, ao mesmo tempo, eu também o encontrara". Mais adiante, ele conclui: "A maioria dessas fotos (...) me ajudava a preencher os espaços em branco (...), a oferecer provas onde antes nada existia".

Vemos, assim, que cada sujeito vai ter suas defesas próprias para lidar com as castrações da vida, e são esses mecanismos que vão decidir como a transmissão vai ocorrer. Os traumas, a doença, os crimes, todas essas vicissitudes vão determinar a transmissão, vão depender do quanto o sujeito suporta simbolicamente esses fatos, e o quanto de bagagem simbólica tem das gerações precedentes. 


\section{Transmissão na cultura}

Assim como cada sujeito tem suas defesas próprias para lidar com o traumático, a sociedade também tem e sofre com os efeitos do que foi silenciado, do que não pôde ser simbolizado. A dimensão negativa da transmissão também aparece na história das sociedades. Nesse sentido, reportamonos a Maria Rita Kehl (2010), que, em seu texto Tortura e Sintoma Social, conta que o Brasil foi o único país da América Latina que perdoou os militares envolvidos na ditadura, sem exigir de sua parte o reconhecimento dos crimes cometidos, nem o pedido de perdão.

Ela lança a hipótese de que esse esquecimento da tortura produz a naturalização da violência como sintoma social no Brasil. Um dado que confirma essa hipótese, segundo a autora, é que a polícia brasileira é a única na América Latina que comete mais crimes de tortura e assassinatos na atualidade do que nos tempos de ditadura. A impunidade através do suposto perdão aos militares produz não só a repetição da tortura mas também tende a provocar um aumento de práticas abusivas por parte dos poderes públicos. Para a psicanálise, o esquecimento que produz sintoma é da ordem do recalque. A autora lança a questão: será que podemos pensar em um inconsciente social, cujas representações recalcadas produzem manifestações sintomáticas? Pensemos: toda sociedade sofre, de algum modo, dos efeitos de sua própria inconsciência. São inconscientes, em uma sociedade, tanto as passagens de sua história relegadas ao esquecimento quanto as vozes silenciadas das minorias, que não encontram meios de se expressar, que ficam excluídas dos processos de simbolização, acabando por produzir repetições assustadoras. Como nos diz Correa, o silêncio da violência e a ruptura dos vínculos geracionais são o denominador comum que percorre a falta de inscrição do sujeito no decorrer das gerações, limitando ou impedindo o acesso à simbolização que organiza uma cadeia significante. Essa falta de inscrição, que ocorre no âmbito individual, a exemplo do romance anteriormente citado, também se dá no âmbito social, a partir do silêncio que opera sobre os fatos traumáticos da História, e que demonstra os efeitos das transmissões negadas sobre o devir da cultura.

\section{Considerações finais}

Vimos, no decorrer do trabalho, que a transmissão fica irremediavelmente ligada a um acontecimento, que produz determinado significado que, por sua vez, pode associarse a qualquer significante transmitido através das gerações, dando-lhe um novo significado. Lembremos que a cadeia significante geracional, se assim se pode dizer, perdurará para sempre, de modo singular em cada sujeito, inclusive podendo ocorrer que certos significantes recalcados em uma geração retornem sob a forma de sintomas em outra. Essa cadeia significantes organiza o que será transmitido na História e o que ficará recalcado desta: "O que a linguagem diz define necessariamente um resto que ela deixa de dizer" (Kehl, 2010, p. 04).

É mobilizador pensar que o que foi recalcado há gerações ainda produz seus efeitos, através do retorno do recalcado, seja sob a forma de violência e tortura, ou seja, na forma de ato, seja sob a tentativa de simbolização que encontramos nas obras literárias e em outras tantas produções culturais. Nesse exemplo de Kehl, observamos aspectos da transmissão transgeracional, sob a forma de fracasso do recalcamento na sociedade e pela impossibilidade de simbolização por parte dos torturadores. A transmissão transgeracional inclui o que não é dito, aquilo que não pôde ser simbolizado; ela é efeito do que foi tentado silenciar, mas que, obrigatoriamente retorna, por processos inconscientes. A 
negação foi o mecanismo usado na tentativa de esquecimento da tortura. Se há algo que diferencia a transmissão transgeracional da intergeracional é o seu retorno, pois a ultima parece ocorrer fundamentalmente por processos simbólicos, enquanto a transgeracional apresenta-se muito mais em atos.

Se traçarmos um paralelo entre os aspectos individual e social, veremos que ambos sofrem os efeitos do recalcamento e das marcas deixadas através dos significantes transmitidos pela História e pelas gerações familiares. Mas, do mesmo modo, tanto o aspecto social quanto o individual encontram meios para lidar com esses significantes, transmitidos, cada um à sua maneira. Vimos, através do livro de Paul Auster, como a produção literária foi uma forma de ressignificar marcas deixadas através dos significantes transmitidos, mostrando como o sujeito pode dar conta da transmissão de um modo criativo. Esse exemplo ilustra o modo como a transmissão intergeracional pode atuar no sujeito, pois houve possibilidade de modificação do que foi transmitido a partir da elaboração daquele que a recebeu, que modificou seu significado, e, acima de tudo, preservou-o simbolicamente. Havia algo a ser questionado, algo que o filho não compreendia do pai:

Não dava para acreditar que existisse um homem assim - destituído de sentimento, que quisesse tão pouco dos outros. E, se não existia um homem assim, significa que havia um outro homem, escondido dentro do homem que não estava ali, e a graça da história, portanto, consistia em descobri-lo. Na condição de que ele estivesse lá para ser descoberto (Auster, 1982/1999, p. 28)

Assim como no romance citado anteriormente, em que o personagem fala do pai como um homem invisível, mas que deixou suas marcas no filho, com os significantes, a questão não é diferente, pois estes, mesmo invisíveis, recalcados, postos de lado, também deixam suas marcas, o que ilustra bem como o significante atua no sujeito e nas sociedades.

Propusemo-nos a investigar neste trabalho a importância da transmissão psíquica na constituição do sujeito e constatamos que a transmissão é necessária e concomitante com a constituição subjetiva. Respondemos o que são as transmissões intergeracional e transgeracional, sendo esta última vista sob um modo diferenciado, a partir dos diferentes modos de negação da castração. Ilustramos as questões sobre a transmissão com aspectos literários - a partir da obra de Paul Auster - e históricos, a partir do artigo de Maria Rita Kehl.

Finalizando, podemos constatar que, tanto na história individual de um sujeito quanto na história das populações, aquilo que não é transmitido simbolicamente, que não pôde ser falado e elaborado, pode ter consequências negativas, e causa estragos no âmbito social e individual, seja pelo retorno do recalcado, seja pelo fato de não haver possibilidade de significação do que foi transmitido. 


\section{Vinícius Oliveira dos Santos}

Docente Convidado na Universidade Luterana do Brasil - ULBRA Campus Torres - RS

Psicólogo - Centro de Referência de Assistência Social - CRAS - Rio Grande do Sul, RS - Brasil.

E-mail: vininofx2004@gmail.com

\section{Mercês Sant'Anna Ghazzi}

Mestrado em Psicologia pela Pontifícia Universidade Católica do Rio Grande do Sul. Professor adjunto da Universidade Luterana do Brasil, Torres - Rio Grande do Sul - RS - Brasil.

E-mail: nmm.ez@terra.com.br

Endereço para envio de correspondência:

Rua Universitária, 1900, Torres, Rio Grande do Sul - RS - Brasil. CEP: 95560-000

Recebido 30/6/2011, 1a Reformulação 30/12/2011, Aprovado 30/3/2012. 
Abraham, N, \& Torok, M. (1995). A casca e o núcleo. São Paulo: Escuta (Trabalho original publicado em 1971)

Auster, P. (1999). A invenção da solidão. (R. Figueiredo, trad.) São Paulo: Companhia das Letras (Trabalho original publicado em 1982).

Bernardino, L. M. F. (Org). (2006). O que a psicanálise pode ensinar sobre a criança, sujeito em constituição. São Paulo: Escuta.

Correa, O. R. (Org). (2000). Os avatares da transmissão psíquica geracional. São Paulo: Escuta.

Dor, J. (2003). Introdução à leitura de Lacan: o inconsciente estruturado como linguagem. Porto Alegre: Artmed.

Eiguer, A. A. (1998). A transmissão do psiquismo entre gerações: enfoque em terapia familiar psicanalítica. São Paulo: Unimarco.

Faimberg, H. (1993). A telescopagem das gerações a propósito da genealogia de certas identificações. In R. Kaës, et al. Transmissão da vida psíquica entre gerações (pp. 71-93). São Paulo: Casa do Psicólogo

Freud, S. (2004). O Recalque. In S. Freud, Edição standard brasileira das obras psicológicas completas de Sigmund Freud (L. A. Hanns, trad., Vol. 1, pp. 175-193). Rio de Janeiro: Imago (Trabalho original publicado em 1915)

Freud, S. (2006a). Totem e tabu. In S. Freud, Edição standard brasileira das obras psicológicas completas de Sigmund Freud (J. Salomão, trad., Vol. 13, pp. 13-163). Rio de Janeiro: Imago (Trabalho original publicado em 1913).

Freud, S. (2006b). Sobre o narcisismo: uma introdução. In S. Freud, Edição standard brasileira das obras psicológicas completas de Sigmund Freud (J. Salomão, trad., Vol. 14, pp. 77-108). Rio de Janeiro: Imago (Trabalho original publicado em 1914).

Freud, S. (2006c). O ego e o id. In S. Freud, Edição standard brasileira das obras psicológicas completas de Sigmund Freud (J. Salomão, trad., Vol. 19, pp. 15-80). Rio de Janeiro: Imago (Trabalho original publicado em 1923).

Gil, A. C. (2010). Como elaborar projetos de pesquisa. (5a. ed). São Paulo: Atlas.
Granjon, E. (2000). A elaboração do tempo genealógico no espaço do tratamento da terapia familiar psicanalítica. In O. R. Correa (Org.), Os avatares da transmissão psíquica geracional (pp. 1743). São Paulo: Escuta.

Inglez-Mazzarella, T. (2006). Fazer-se herdeiro: a transmissão psíquica entre gerações. São Paulo: Escuta.

Jerusalinsky, J. (2005). Quem é o outro do sujeito na primeira infância? Considerações sobre o lugar da família na clinica com bebês (pp. 01-14). Recuperado em 07 março, 2010, de http:// www.estadosgerais.org/encontro/tv/pt/trabalhos.php

Jorge, M. A. C. (2005). Fundamentos da psicanálise: de Freud a Lacan. (4a.ed., Vol. 1). Rio de Janeiro: Jorge Zahar.

Kaës, R. (1997). Os dispositivos psicanalíticos e as incidências da geração. In A. Eiguer, et al. A transmissão do psiquismo entre gerações: enfoque em terapia familiar psicanalítica (pp. 5-19). São Paulo: Unimarco.

Kehl, M. R. (2010). Tortura e sintoma social. In E. Teles \& V. Safatle, O que resta da ditadura. São Paulo: Boitempo.

Lacan (1998a). Os escritos técnicos de Freud (V. Ribeiro, trad., Livro 1). Rio de Janeiro: Jorge Zahar (Trabalho original publicado em 1954).

Lévi-Strauss, C. (1973). A eficácia simbólica. In C. Lévi-Strauss, Antropologia estrutural. Rio de Janeiro: Tempo Brasileiro (Trabalho original publicado em 1973).

Mezan, R. (1994). Pesquisa teórica em psicanálise. Psicanálise e Universidade, 2, 51-75.

Quinet, A. (2007). As 4+1 condições da análise. (11a. ed.). Rio de Janeiro: Jorge Zahar.

Rosa, M. Debieux. (2001). O não-dito familiar e a transmissão da história. Psychê - Revista de Psicanálise, 8(5), 123-137.

Saussure, F. de. (1993) Curso de linguística geral. São Paulo: Cultrix.

Szejer, M. (1997). Nove meses na vida da mulher: uma abordagem psicanalítica da gravidez e do nascimento. (M. N. B. Benetti, trad.). São Paulo: Casa do Psicólogo.

Whale, J. (Diretor). (1933). O homem invisível. [DVD]. Los Angeles, EUA: Universal Pictures. 